\title{
Comprehensive Evaluation of Antioxidant Potential of Selected Osbeckia species and their in vitro Culture, Purification and Fractionation
}

\author{
Bosco Lawarence and Murugan $\mathrm{K}$
}

\section{Bosco Lawarence and Murugan $\mathrm{K}$}

Plant Biochemistry and Molecular Biology Laboratory, University College, Trivandrum, Kerala, INDIA.

Correspondence

Mr. Bosco Lawarence, Plant Biochemistry and Molecular Biology Laboratory, University College, Trivandrum- 695034, Kerala, INDIA.

Phone no: 9446312540

E-mail: boscotvm@gmail.com

History

- Submission Date: 28-05-2017

- Review completed: 22-06-2017.

- Accepted Date: 02-07-2017

DOI : 10.5530/pj.2017.5.107

Article Available online

http://www.phcogj.com/v9/i5

Copyright

(C) 2017 Phoog.Net. This is an openaccess article distributed under the terms of the Creative Commons Attribution 4.0 International license.

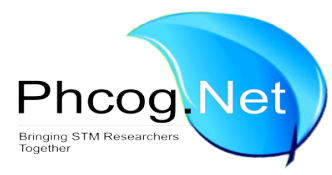

\begin{abstract}
Background: Health-benefit properties of natural pigments have been intensely studied, especially the anthocyanins. In the last few decades, research on anthocyanins has attracted biologists by the increasing evidence of their health beneficial effects. Osbeckia, belongs to Melastomataceae and is well-known for colouring pigments and other bioactive compounds. In the present study, total anthocyanin and antioxidant capacity indicators were evaluated from 8 Osbeckia spp. and anthocyanin was extracted from in vitro cultures of 0 . aspera and $O$. reticulata. Materials and Methods: The antioxidant effect was studied using ABTS (2, 2'-azino-bis-3-ethyl benzthiazoline-6-sulphonic acid) radical cation decolourisation assay, the FRAP, the scavenging ability of hydroxyl radicals and the superoxide anion scavenging activity. Anthocyanin extracted from in vitro cultures were purified and fractionated using column chromatography and LC-MS MS analysis. Results: In vitro cultures of $O$. aspera was obtained in MS medium fortified with various combinations of Benzyl Adenine (BA), Naphthalene acetic acid (NAA) and 2,4-D. The chromatograms of $O$. aspera revealed the presence of malvidin-3 -diglucoside, peonidin, delphinidin and cyanindin whereas $O$. reticulata cultures accumulated large amounts of malvidin, cyanindin and cyanidin aglycone. The purified anthocyanins of these species were evaluated for their antioxidant potential and was found more remarkable than the crude extracts. Conclusion: Osbeckia species are rich in anthocyanin and therefore display potential AOX power. $O$. aspera and $O$. reticulata callus was induced in vitro production of anthocyanins. The pool of anthocyanins was purified and fractionated by LCMS/MS and AOX assays were performed with the purified anthocyanin which showed higher level activities.

Key words: Antioxidant capacity, Osbeckia spp., Anthocyanins, Free radicals, Reactive oxygen species.
\end{abstract}

\section{INTRODUCTION}

All over the world, people utilized the herbals for the treatment of various ailments before the advent of allopathic medicine. Medicinal plants have been a major source for ayurvedic drug development. Plant extracts and products are used in the treatment of bacterial, fungal and viral infections. Natural phytochemicals are known to contain lead molecules that can be used for therapeutic purposes or as precursor for the synthesis of novel useful drugs. The natural products play an important role in drug development in pharmaceutical industry. Currently plants are used as a source of medicine and also important in terms of health care system.

The genus Osbeckia contains about 12 species. Species of this genus are used in traditional medicine for stress mitigation, detoxicating, hematischesis and also as astringent. Chemical constituents reported from O. crinita, O. aspera and O. chinensis showed the presence of flavonoids, organic acid and steroids.
In experimental studies, the aqueous extract of Osbeckia was shown to protect cells from hepatotoxicity induced by carbon tetrachloride. ${ }^{1,2} \mathrm{D}$-galactosamine, $\mathrm{t}$-butylhydroperoxide and bromobenzene in vitro. ${ }^{3}$ The aqueous extract of Osbeckia provided significant protection against paracetamol-induced in vivo liver injury, as assessed by histological changes and liver enzyme levels. In vitro experiments were also performed to test the ability of the aqueous plant extract to protect freshly-isolated rat hepatocytes against damage produced by 2,6-dimethyl $\mathrm{N}$-acetyl p-quinoneimine (2,6-diMeNAPQI), a stable analogue of the toxic metabolite of paracetamol. Thus, there is good evidence that the aqueous extract of Osbeckia has direct protective effects on hepatocytes, and therefore be involved in inducing immune system against viral hepatitis. Antioxidant and immune modulatory effects were investigated with $O$. aspera and O. wynaadensis. ${ }^{4}$

Cite this article : Bosco Lawarence and Murugan K. Comprehensive Evaluation of Antioxidant Potential of Selected Osbeckia species and their in vitro Culture, Purification and Fractionation. Pharmacog J. 2017;9(5):674-82. 
Osbeckia octandra was studied for its hepatoprotective activity. Further O. octandra, O. chinensis and O. nepalensis were showed to exhibit antidiabetic activity. ${ }^{5}$

Despite all these reports, the use of Osbeckia fruits and flowers by ethnic people was highly ignored by investigators. Osbeckia chinensis fruits were used by the Meithi community of Manipur to obtain a medicinally important violet dye and this dye was used in olden days for colouring mouth. ${ }^{6}$ The crushed fruits and flowers are soaked in local made wine or country liquor for best results. The violet dye being anthocyanins, the brightly coloured flowers and fruits also need to be investigated for medicinal properties. Anthocyanins represent one of the most widely distributed classes of plant flavonoids. Apart from their coloring effects, anthocyanins show ability to prevent lipid oxidation, scavenging activity against various artificially generated free radicals. The common aglycon forms of anthocyanidins are cyanidin, delphinidin, peonidin, petunidin, malvidin, and pelargonidin. The prevalent sugar moieties are glucose, rhamnose, xylose, galactose, arabinose, and fructose.

The genus Osbeckia is also facing threats of extinction due to pollution and man-made destructive-activities. No authentic records of micro propagation works were reported except that of O. octandra which was used as a horticultural crop in landscaping. The present work is to evaluate the anti-oxidant activity of the anthocyanins obtained from the selected species of Osbeckia and to standardise protocols for the micro propagation of Osbeckia aspera and Osbeckia reticulata.

\section{MATERIALS AND METHODS}

\section{The Plant material}

Flowers of Osbeckia sps. for the present study were obtained from various parts of Idukki district of Kerala such as Munnar hills, Wagamon and Peerumed. Osbeckia aspera, is a perennial shrub distributed both in tropics and sub tropics. Although the plant is propagated naturally by vegetative means as well as through seeds, seed derived plantlets were found to be less frequent in natural habitat and distribution appear in fragmented patches derived from root stocks. Osbeckia reticulata, is a small tree frequently seen in temperate habitats and is distributed above 3000 feet in Western Ghats. Osbeckia aspera was well established in the green house, but $O$. reticulata failed to acclimatize with the greenhouse conditions and did not remain alive beyond six months. Identity of the plants were confirmed by referring floras and authenticated by herbaria of Jawaharlal Nehru Tropical Botanical Garden and Research Institute, Palode, Trivandrum.

\section{In vitro culture}

The collected plantlets were reared in green house of the college Botanical garden and stem segments and leaf cuttings from healthy, disease free plants were used as explants. The explants were subjected to surface sterilisation using $10 \%$ teepol solution followed by rinsing in tap water for $60 \mathrm{~min}$. Then, the stem cuttings were immersed in ethanol $70 \%(\mathrm{v} / \mathrm{v})$ for $30 \mathrm{~s}$ and, finally mercuric chloride or sodium hypochlorate was used. Ethanol treatment was found hazardous in the case of leaves. In the last step, explants were washed in distilled and autoclaved water.

After sterilisation nodal segments $(2-3 \mathrm{~cm})$ were used for multiple shoot induction and inter nodal fragments and leaf cuttings were used for direct organogenesis and callus induction. The explants were transferred to MS culture medium supplemented with various phytohormones, besides the control group (without growth regulators). During the entire process of in vitro culture, the plantlets were kept in $2.5 \times 15 \mathrm{~cm}$ test tubes. The MS culture media was supplemented with vitamins, sucrose (30 gm /L), and agar (7 gm /L). The culture media $\mathrm{pH}$ was adjusted to $5.7 \pm 0.1$. Media were sterilized by autoclaving for $15 \mathrm{~min}$ at $120^{\circ} \mathrm{C}$ and $15 \mathrm{lbs}$ of pressure.
Clonal fidelity of the regenerated plants was ascertained by morphological and histological evaluation. All experiments were conducted in a completely randomized design.

\section{Estimation of Anthocyanin content and antioxidant potential}

Protocol by Sutharut and Sudarat was used for the estimation of anthocyanin content in flowers. The absorbance was read at 510 and $700 \mathrm{~nm}$ against distilled water as blank. ${ }^{7}$

Aqueous acidified methanol and ethanol have been most commonly used in the extraction of anthocyanins. Methanol is not preferred for food use as it is toxic. Ethanol is the most acceptable one for use in food industry. Silica gel, Amberlite IRC 80, Amberlite IR 120, DOWEX 50WX8, Amberlite XAD4 and Amberlite XAD7, were examined for the purification of anthocyanins.

LC- MS/MS analyses were performed on an Agilent 6410A Triple Quad LC-MS/MS system. Briefly, a $100 \mu \mathrm{L}$ sample was injected onto a Reliasil $4.6 \times 250 \mathrm{~mm}, 5-\mu \mathrm{m}$ c18 column equilibrated in 95:5 A:B where A was $0.1 \%$ Acetic acid and $B$ was acetonitrile. Flow rate was $0.5 \mathrm{~mL} / \mathrm{min}$. Anthocyanins were eluted through application of a linear gradient to 80:20 A:B in 25 min. Data dependent MS/MS and MS3 were performed on abundant precursor ions to elucidate chemical structures. Precursor ion scans were obtained in the range $\mathrm{m} / \mathrm{z} 600-1400$ and all data manipulation was within Xcalibur software, version 2.0.7.

To estimate the anti-oxidant activity of the plants the flower petal extracts $(20 \mu \mathrm{l})$ were added to $0.5 \mathrm{ml}$ of methanolic solution of DPPH and $0.48 \mathrm{ml}$ of methanol. The mixture was allowed to react at room temperature for 30 minutes. Methanol served as the blank and DPPH in methanol, without the leaf extracts, served as the positive control. After 30 minutes of incubation, the discolouration of the purple colour was measured at $518 \mathrm{~nm}$ in a spectrophotometer. The radical scavenging activity was calculated. ${ }^{8}$

The antioxidant effect of the extracts was also studied using ABTS (2,2'-azino-bis-3-ethyl benzthiazoline-6-sulphonic acid) radical cation decolourisation assay. Radical cations (ABTS+) were produced by reacting ABTS solution $(7 \mathrm{mM})$ with $2.45 \mathrm{mM}$ ammonium persulphate. The mixture was allowed to stand in the dark at room temperature for 12-16 hours before use. Aliquots $(0.5 \mathrm{ml})$ of the different extracts were added to $0.3 \mathrm{ml}$ of ABTS solution and the final volume was made up to $1 \mathrm{ml}$ with ethanol. The absorbance was read at $745 \mathrm{~nm}$ in a spectrophotometer and the per cent inhibition was calculated. ${ }^{9}$

The FRAP assay was performed according to methods described by Benzie and Strain. ${ }^{10}$ FRAP values, expressed as mmol of $\mathrm{Fe}$ (II) equivalent per $\mathrm{g}$ plant material, was obtained by comparing the absorption change in the test mixture with doses obtained from $\mathrm{Fe}(\mathrm{II})$ standard concentrations curve.

The chelating activity was determined by the method of Dinis et al. ${ }^{11}$ The metal chelating capacities of the extracts were expressed as mg EDTA equivalents/100 g extract. A modified thiobarbituric acid-reactive substance (TBARS) assay was used to measure Inhibition (\%) of lipid peroxidation. ${ }^{12}$ Total antioxidant capacity of the plants was evaluated by the phosphomolybdenum method according to the procedure describe by Prieto and his colleagues. ${ }^{13}$ The ability of extracts to scavenge hydrogen peroxide was estimated according to the method of Ruch et al. ${ }^{14}$ The scavenging ability of hydroxyl radicals is measured by the method of Kunchandy and Rao. ${ }^{15}$ The superoxide anion scavenging activity was measured as described by Robak and Gryglewski. ${ }^{16}$ 


\section{Statistical analysis}

All the experiments were done in 12 replicates. The results were expressed as mean \pm SD $(n=10)$. SPSS-7.5 version was used for the entire analysis. $\mathrm{P}<0.05$ was considered as significant.

\section{RESULTS}

Antioxidant-based drug formulations are used for the prevention and treatment of complex diseases like atherosclerosis, stroke, diabetes, Alzheimer's disease and cancer. Anthocyanins are flavonoids, the natural pigments giving wide colour range in plants and showing antioxidant potential. The chemical structure of these molecules seems to be responsible for this potential. Anthocyanins are the most oxidized flavonoids with the $\mathrm{C}$ ring fully unsaturated with a hydroxyl group.

Anthocyanin was extracted from the tissues using a mixture of ethanol and water in the ratio $70: 30$ acidified with $1 \% \mathrm{HCl}$ without any accelerator and energy sources. The solid-liquid separation was done by filtration and centrifugation methods. Anthocyanins were isolated and purified by column chromatography in silica gel and subsequently using amber lite. Amber lite XAD7HP had the highest capacity and desorption ratio. As free sugar was the degradation factor for anthocyanins, the free sugar concentration before and after purification were tested and it was found decreased significantly.

There are several studies regarding extraction of anthocyanins by solvents. Extraction of anthocyanin from eggplant peel with acidified alcoholic solvent (ethanol:water:HCl;70:30:1, v/v/v) appeared more efficient than those without ethanol. ${ }^{17}$ The anthocyanin extraction from black rice using $70 \%$ methanol obtained higher anthocyanin concentration than $70 \%$ ethanol and it was more effective than water and $70 \%$ acetone. However, ethanol has been used in the extraction of anthocyanins from black rice because of low toxicity application in food industries compared to methanol. ${ }^{18}$

The anthocyanin content of the flowers varied considerably among the species (Table 1). Osbeckia aspera was found to contain the highest anthocyanin content followed by Osbeckia virgata and O. reticulata. Within O. aspera, anthocyanin content varied from $20.5 \mathrm{mg} / \mathrm{g}$ to $37.61 \mathrm{mg} / \mathrm{g}$ in different varieties. Flowers of the wightiana variety of Osbeckia aspera is found to be the best source of anthocyanin among them. Osbeckia reticulata had $30.3 \mathrm{mg} / \mathrm{g}$ and $O$. virgata was found to contain $32.2 \mathrm{mg} / \mathrm{g}$. LC-MS/MS analysis of purified anthocyanin from Osbeckia aspera and Osbeckia reticulata contain unique fractions of anthocyanins, ie, O. aspera was rich in malvidin-3 -diglucoside, peonidin, delphinidin and cyanindin, whereas, $O$. reticulata showed large amounts of malvidin, cyanindin and cyanidin aglycone.

The two species O. aspera and O. reticulata responded differently in in vitro culture environments. High concentration of cytokinins was found to be sufficient for the rapid sprouting and multiple shoot induction in
O. reticulata. $3.5 \mathrm{mg} / \mathrm{L}$ of BAP produced 18 shoots and $4.2 \mathrm{mg} / \mathrm{L}$ of KIN produced 15 shoots. In $O$. aspera the most suitable medium for shoot induction was the combination of BA and NAA, ie, $2.5 \mathrm{mg} / \mathrm{L} \mathrm{BA}$ and $0.5 \mathrm{mg} / \mathrm{L}$ NAA produced 21.28 shoots, $2.5 \mathrm{mg} / \mathrm{L} \mathrm{BA}$ alone produced 7.57 shoots and $3 \mathrm{mg} / \mathrm{L} \mathrm{KIN}$ alone produced 5.57shoots. In O. reticulata, addition of auxins along with BA or NAA resulted in slowing down of shoot proliferation and induced irregular differentiation of tissues. Callusing in both species was normal in equal concentrations auxins and cytokinins. Combinations of BA along with NAA and IBA produced compact tissues with morphogenesis and combination of BA with 2, 4-D produced white friable callus. Combination of either of the cytokinins along with both NAA and IBA and higher concentrations of sucrose in the medium ( 2 to 2.5 fold) induced synthesis of anthocyanin in friable callus, but darkening of the callus and subsequent death resulted within 5-7 days of the beginning of anthocyanin production (Figure 1a). The highest content of anthocyanin in Osbeckia aspera, (ie, $94.4 \mathrm{mg} / \mathrm{g}$ ) was obtained in $8 \%$ sucrose, $0.5 \mathrm{mg} / \mathrm{L} \mathrm{BA}$ and $0.5 \mathrm{mg} / \mathrm{L} \mathrm{2,4-} \mathrm{D} \mathrm{(Figure} 1 \mathrm{~b}$ ). In O. reticulata the highest content $(69.8 \mathrm{mg} / \mathrm{g})$ of anthocyanin producing callus was obtained in half strength MS medium supplemented with $8 \%$ sucrose, $1.2 \% \mathrm{BA}$ and $1.4 \%$ 2,4-D (Table 2).

Anthocyanin content of the callus was found higher than the flower tissues of both the species. Anthocyanin content and profile of the in vitro raised plants were similar to the naturally grown plants.

\section{Total Antioxidant (AOX) potential}

The total antioxidant activities of different Osbeckia species anthocyanin extracts are narrated in Table 3. The values of the total AOX potential of anthocyanin extracts expressed in terms of equivalents of ascorbate. This assay gives an estimate of the overall AOX potential of anthocyanin. ${ }^{13}$ Anthocyanins reduce Mo (VI) into Mo (V) and forms a green coloured phosphomolybdenum $\mathrm{V}$ complex, which shows maximum OD at $700 \mathrm{~nm}$. O. aspera anthocyanin extract showed higher activity in the range of $100 \mu \mathrm{g} / \mathrm{ml}$ in comparison to other Osbeckia species, whereas the O. leschenaultiana showed least activity. Similarly, Baskar et al. showed variable total AOX activity among different banana peel extract under different solvent and incubation conditions. ${ }^{19}$ Purified anthocyanin of $O$. aspera and $O$. reticulate showed similar activity at $25 \mu \mathrm{g} / \mathrm{ml}$.

\section{DPPH radical scavenging assay}

The Table 3 displayed shows DPPH radical scavenging potential of anthocyanin from different Osbeckia species. The mean values across the concentration range, clearly indicates the potential of $O$. aspera in scavenging DPPH free radicals as 61.8 percentage inhibition at $100 \mu \mathrm{g} / \mathrm{ml}$ when compared to other Osbeckia species. DPPH radicals react with reducing agents, during which the electrons become paired off and the solution loses colour stoichiometrically depending on the number of electrons taken up i.e., the solution gradually reduced to yellowish

Table 1: Anthocyanin content of Osbeckia species

\begin{tabular}{cccc}
\hline NAME & HABITAT & ALTITUDE ( feet) & ANTHOCYANIN (mg/gm) \\
\hline Osbeckia aspera (L.) var. travancorica & Midland meadows & 3000 & 42.57 \\
Osbeckia aspera (L.) var. wightiana & Evergreen and moist deciduous forests and grasslands & $1400-4000$ & 57.61 \\
Osbeckia aspera (L.) var. aspera & Tropical Low land, Evergreen forest, Plains & $400-700$ & 2100 \\
Osbeckia gracilis Bedd. & Moist deciduous and shola forests & 3500 & 31.22 \\
Osbeckia leschenaultiana DC. & High altitude shola forests & 4000 & 37 \\
Osbeckia reticulata Bedd. & High altitude grasslands & $400-700$ & 32.56 \\
Osbeckia virgata D. Don ex Wight \& Arn. & Evergreen and moist deciduous forests, plains & $2100-4000$ & 44.33 \\
Osbeckia wynaadensis Clarke & Waterlogged semi-evergreen and evergreen forests & & 24.76 \\
\hline
\end{tabular}



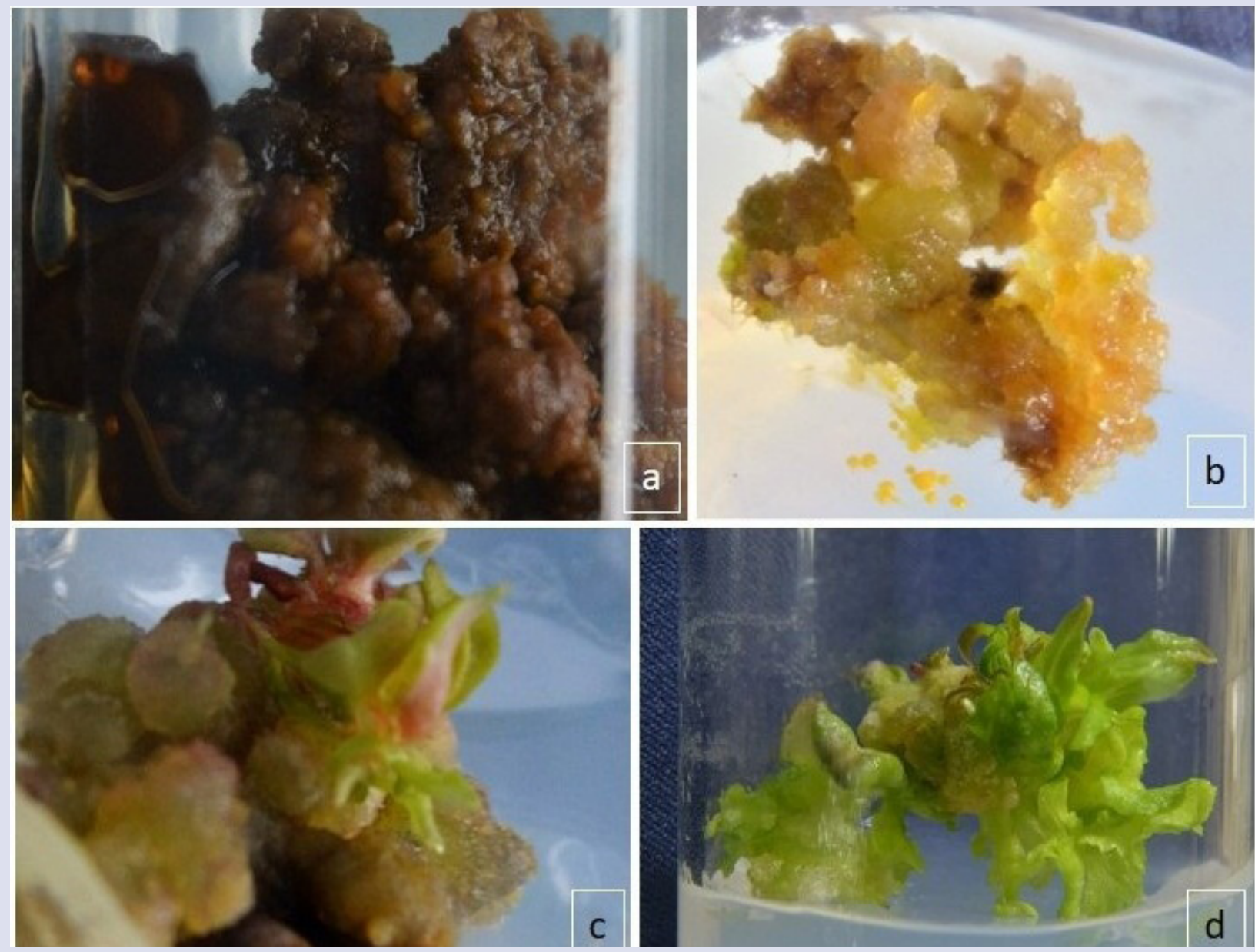

Figure 1: a - Anthocyanin rich callus produced in $1.4 \mathrm{mg} / \mathrm{l} 2,4 \mathrm{D}$ and $1.2 \mathrm{mg} / \mathrm{l} \mathrm{BA}$ in 0 . reticulata; $\mathrm{b}$ - friable callus produced in $0.5 \mathrm{mg} / \mathrm{l}$ of 2 , 4-D and $0.5 \mathrm{mg} / \mathrm{I} \mathrm{BA}$ in O.aspera; - Multiple shooting in O. reticulata; $\mathrm{d}$ - shoots produced in $2.5 \mathrm{mg} / \mathrm{L} \mathrm{BA}$ and $0.5 \mathrm{mg} / \mathrm{l} \mathrm{NAA}$ in 0 . aspera.

product viz., diphenylpicryl hydrazine, with the addition of the anthocyanin. Purified anthocyanin of $O$. aspera and $O$. reticulata revealed more remarkable DPPH scavenging activity at $25 \mu \mathrm{g} / \mathrm{ml}$.

\section{ABTS radical scavenging capacity}

Table 3 indicates the ABTS radical scavenging capacity of anthocyanin at various concentrations from different Osbeckia species. From the results, it may be interpreted that O. aspera and O.reticulata, among all species, inhibit or scavenge the radical in a dose dependent manner with highest percentage inhibition ( $47.6 \%$ and $40.2 \%$ respectively) noticed at $100 \mu \mathrm{g} / \mathrm{ml}$. Studies by Subhasree et al. ${ }^{20}$ determined the scavenging activity on ABTS radical from selected green leafy vegetables which were at par with the present results. Purified anthocyanin of $O$. aspera and O. reticulata displayed more activity at $25 \mu \mathrm{g} / \mathrm{ml}$ concentration.

\section{Lipid peroxidation inhibition assay}

Inhibition of lipid peroxidation by anthocyanin at various concentrations from different Osbeckia species is represented in the Table 3. Lipid peroxides are unstable and decompose to form reactive carbonyl molecules responsible for damage of DNA, protein, unsaturated fatty acids, generation of life style diseases. Most abundant among them is malondialdehyde (MDA), which reacts with thiobarbituric acid (TBA) to form a pinkish chromogen. The decrease in the MDA levels in the presence of increased dose of anthocyanin suggests the role of anthocyanins as antioxidants. TBARS assay was used to determine the anti-lipid peroxidation properties of the anthocyanins. The result values obtained indicate a moderate percentage inhibition with $O$. aspera exhibiting highest inhibition among other species at $100 \mu \mathrm{g} / \mathrm{ml}$. Remarkable lipid peroxidation inhibition, ie, 74 and 62.3 was showed by the purified anthocyanin of O. aspera and O. reticulata at $25 \mu \mathrm{g} / \mathrm{ml}$ (Table 4).

\section{Hydrogen peroxide $\left(\mathrm{H}_{2} \mathrm{O}_{2}\right)$ scavenging activity}

Anthocyanins are polyphenols can donate electrons to $\mathrm{H}_{2} \mathrm{O}_{2}$ and converted to $\mathrm{H}_{2} \mathrm{O} . \mathrm{H}_{2} \mathrm{O}_{2}$ is a signaling molecule that inactivates a few enzymes directly, usually by oxidation of essential thiol group $(-\mathrm{SH})$ leads to toxic effects that can cross membranes and reacts with $\mathrm{Fe}^{2+}$ and $\mathrm{Cu}^{2+}$ ions to form hydroxyl radical. Osbeckia species showed insignificant AOX activity i.e., ranged from 14.5 to $25.4 \%$. Synthetic antioxidants such as quercetin and ascorbate standards yielded $66.1 \%$ and $75.5 \% \mathrm{H}_{2} \mathrm{O}_{2}$ scavenging activity. Purified anthocyanin of O. aspera and O. reticulata showed increased activity ie, 49.6 and 41.2 percentage respectively at $25 \mu \mathrm{g} / \mathrm{ml}$. 


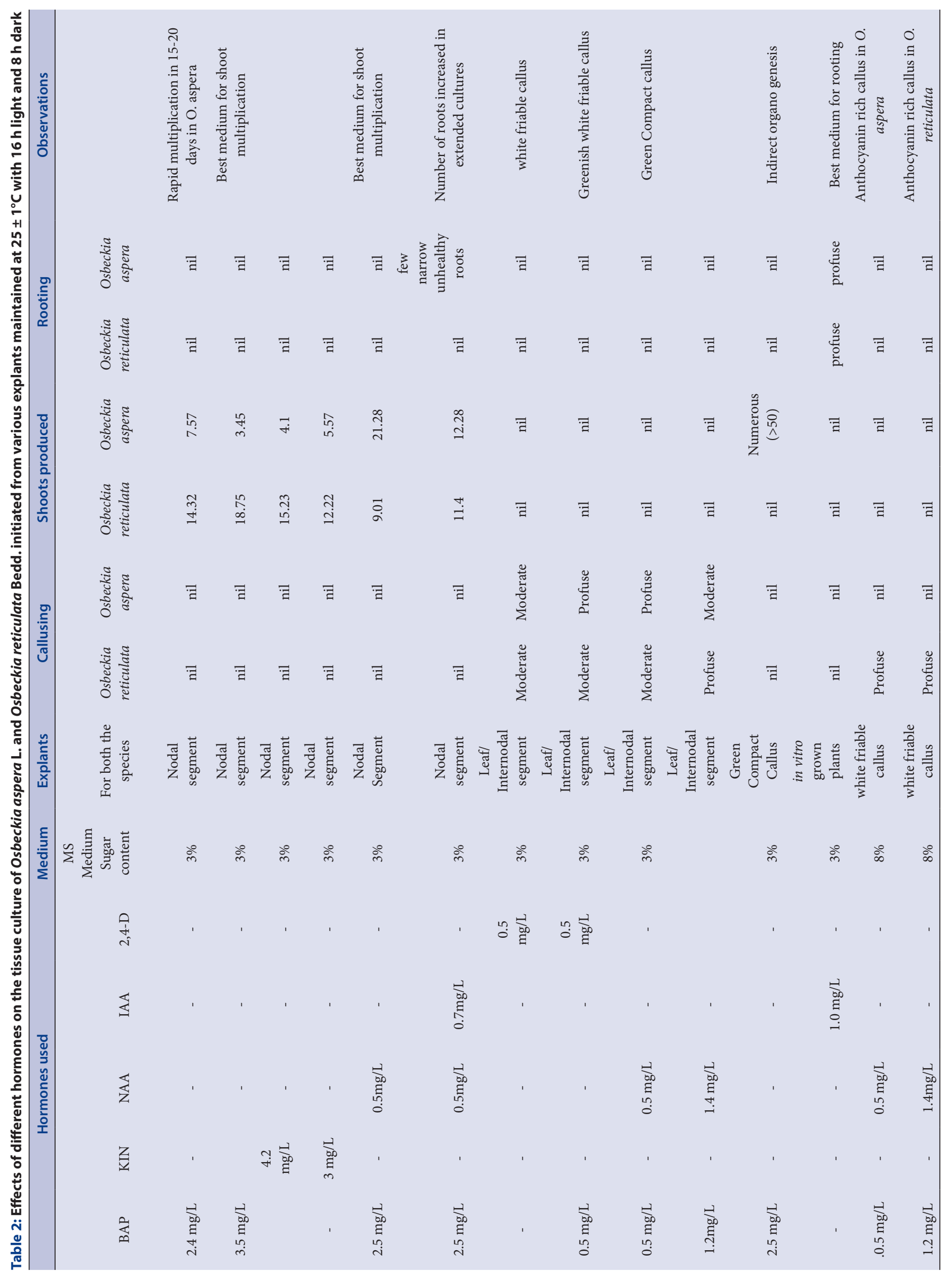


Table 3: Anti-oxidant activity of Osbeckia species at $100 \mu \mathrm{g} / \mathrm{ml}$ concentration

\begin{tabular}{|c|c|c|c|c|c|c|c|c|c|}
\hline Species of Osbeckia studied & $\begin{array}{c}\text { Metal } \\
\text { chelating }\end{array}$ & $\begin{array}{l}\text { Radical } \\
\text { scavenging } \\
\text { DPPH- }\end{array}$ & $\begin{array}{l}\text { Metal } \\
\text { reducing } \\
\text { activity, } \\
\text { FRAP- }\end{array}$ & $\begin{array}{l}\text { Radical } \\
\text { scavenging } \\
\text { ABTS }\end{array}$ & $\begin{array}{l}\text { Total AOX } \\
\text { activity }\end{array}$ & $\begin{array}{l}\text { LPX } \\
\text { assay }\end{array}$ & $\mathrm{H}_{2} \mathrm{O}_{2}$ & $\mathrm{O}_{2}$ & $\mathrm{OH}$ \\
\hline & $\%$ & $\%$ & $\mathrm{mM} \mathrm{Fe}(\mathrm{II}) / \mathrm{g}$ & $\begin{array}{c}\text { Trolox } \mu \mathrm{mol} / \mathrm{g} \\
\text { DW }\end{array}$ & $\mathrm{mg} \mathrm{AAE} / \mathrm{g}$ & $\%$ & $\%$ & $\%$ & $\%$ \\
\hline Osbeckia aspera var. aspera & 37.8 & 61.8 & 27.8 & 47.3 & 5.85 & 47.6 & 25.4 & 33.6 & 52.2 \\
\hline Osbeckia aspera var.whitiana & 30.4 & 59.5 & 21.4 & 49.7 & 4.9 & 37.8 & 19.6 & 27 & 37.6 \\
\hline Osbeckia leschenaultiana & 31 & 55.3 & 20.5 & 42.8 & 3.9 & 39.6 & 18.8 & 25.6 & 39.8 \\
\hline Osbeckia reticulata & 32.3 & 62.8 & 23.2 & 53.7 & 5 & 35.3 & 20 & 24.3 & 50.3 \\
\hline Osbeckia gracilis & 28 & 57.4 & 25.6 & 47.4 & 3.7 & 40.2 & 23.1 & 29.8 & 42.3 \\
\hline Osbeckia virgata & 27 & 60.4 & 17.9 & 48.9 & 3.5 & 31.6 & 21.3 & 23 & 40 \\
\hline Osbeckia. wynadensis & 25.6 & 58.3 & 16.4 & 45.3 & 3.1 & 30.5 & 22.2 & 22 & 41.5 \\
\hline $\begin{array}{l}\text { Osbeckia. aspera var. } \\
\text { travancorica }\end{array}$ & 28 & 59.4 & 15.9 & 47.6 & 4.2 & 29 & 14.5 & 20 & 39.7 \\
\hline
\end{tabular}

Table 4: AOX Potential of purified anthocyanin of Osbeckia aspera and Osbeckia reticulata from in vitro callus cultures at $25 \mu \mathrm{g} / \mathrm{ml}$ concentration

\begin{tabular}{|c|c|c|c|c|c|c|c|c|c|}
\hline $\begin{array}{l}\text { Species of Osbeckia } \\
\text { studied }\end{array}$ & $\begin{array}{l}\text { Total AOX } \\
\text { activity }\end{array}$ & $\begin{array}{l}\text { Radical } \\
\text { scavenging } \\
\text { DPPH- }\end{array}$ & $\begin{array}{l}\text { Metal } \\
\text { reducing } \\
\text { activity, } \\
\text { FRAP- }\end{array}$ & $\begin{array}{l}\text { Radical } \\
\text { scavenging } \\
\text { ABTS }\end{array}$ & $\begin{array}{c}\text { Metal } \\
\text { chelating }\end{array}$ & $\mathrm{O}_{2}$ & $\mathrm{H}_{2} \mathrm{O}_{2}$ & $\mathrm{OH}$ & $\begin{array}{l}\text { LPX } \\
\text { assay }\end{array}$ \\
\hline & $\mathrm{mg} \mathrm{AAE} / \mathrm{g}$ & & $\mathrm{mM} \mathrm{Fe}(\mathrm{II}) / \mathrm{g}$ & $\begin{array}{c}\text { Trolox } \mu \mathrm{mol} / \mathrm{g} \\
\text { DW }\end{array}$ & $\%$ & $\%$ & $\%$ & $\%$ & $\%$ \\
\hline Osbeckia aspera & 6.2 & 79.8 & 50.4 & 57.2 & 76.2 & 45.4 & 49.6 & 68.5 & 74 \\
\hline Osbeckia reticulata & 5.76 & 73.5 & 48.7 & 68.9 & 65.8 & 44.2 & 41.2 & 63.9 & 62.3 \\
\hline
\end{tabular}

\section{Superoxide radical $\left(\mathrm{O}_{2}^{-}{ }^{-}\right)$scavenging activity}

Endogenously, $\mathrm{O}_{2}{ }^{-}$are produced in substantial amounts by diverse biological processes and are toxic to cellular components i.e., a precursor of the most reactive oxygen species (ROS), contributing to tissue damage and various diseases. Anthocyanins of $O$. aspera exhibited optimal ability in scavenging $\mathrm{O}_{2}^{--}$, when compared to the standards quercetin and ascorbate (Table 2). The results suggest that the O. aspera have superoxide radical scavenging activity which can be of significant interest in health prospects in reducing the level of $\mathrm{O}_{2}{ }^{-}$which is elevated during oxidative stress in the body. Potential superoxide anion scavenging was noticed with purified anthocyanin of O. aspera and O. reticulata at $25 \mu \mathrm{g} / \mathrm{ml}$.

\section{Hydroxyl radical $(-\mathrm{OH})$ scavenging activity}

The $\mathrm{OH}$ is one of the ROSs generated in the body. These radicals are produced through various biological reactions such as Iron (II)-based Fenton reaction. The scavenging capacity of $O$. aspera may be attributed by their phenolic compounds with the ability to accept electrons, which can combine with free radical competitively to decrease hydroxyl radicals. Umamaheswari and Chatterjee analyzed in vitro varied antioxidant of the different solvent fractions of Coccinia grandis leaf extracts. ${ }^{21}$ The present AOX potential of Osbeckia species are comparable with the above results. Purified anthocyanin of both the species showed remarkable activity ie 68.5 and 63.4 percentage respectively at $25 \mu \mathrm{g} / \mathrm{ml}$ (Table 4 ).

\section{Metal chelating activity}

Iron is an essential element required for normal physiology, but excess of it may leads in cellular injury i.e., it undergo Fenton reaction, these reduced metals may form reactive hydroxyl radicals and thereby contribute to oxidative stress. ${ }^{22}$ Ferrozine can quantitively form complexes with $\mathrm{Fe}^{2+}$. In the presence of chelating agents, the complex formation is broken, leading to less red coloration of the complex. The metal chelating activity of Osbeckia species was presented in the Table 3. In this assay, Osbeckia aspera registered higher metal chelating activity. The scavenging potential and metal chelating ability of the antioxidants are dependent upon their unique phenolic structure and the number of hydroxyl groups. Raghavan et al.,analyzed free radical scavenging potential of Chlorophytum tuberosum and the values were at par with Osbeckia aspera. ${ }^{23}$ Purified anthocyanin of O. aspera and O. reticulata showed a twofold higher activity at $25 \mu \mathrm{g} / \mathrm{ml}$ (Table 4 ).

\section{FRAP assay}

The results of the FRAP assay of Osbeckia species are reported in the Table 3. All species showed considerable amounts of antioxidant effects from $15.9 \mu \mathrm{mol}$ of $\mathrm{FeSO}_{4} / \mathrm{g}$ of anthocyanin equivalent to $27.8 \mu \mathrm{mol}$ of $\mathrm{FeSO}_{4} / \mathrm{g}$ in DMSO extract. Also, FRAP values, in other species were optimal $(P<0.05)$ and was comparable to $\alpha$-tocopherol $(10 \mathrm{mg} / \mathrm{L})$ as the reference compound. Purified anthocyanin of O. aspera and O. reticulata displayed optimal activities than crude extracts.

\section{DISCUSSION}

Plants display diverse secondary metabolites such as alkaloids, polyphenols, saponins, carotenoids and other molecules. Most of them are proven therapeutic compounds in one way or other. Antioxidant potentials of these phytochemicals are indirectly involved in curing many human diseases including cancer, inflammation etc. For example, Subhasree et al evaluated antioxidant potential in selected green leafy vegetables. ${ }^{20}$ Umamaheswari and Chatterjee analyzed in vitro antioxidant activities of the fractions of Coccinia grandis leaf extract. ${ }^{21}$ Saito et al. extensively 
screened edible herbal extracts with potent scavenging activity against superoxide anions. ${ }^{22}$ Raghavan et al., reported free radical scavenging potential of Chlorophytum tuberosum. ${ }^{23}$ Fernando et al., evaluated antioxidant potential of some species of Bomarea of Alstroemeriaceae. ${ }^{24}$ Venugopalan and Revathy proved antioxidant activity of Cassia fistula flower extracts. ${ }^{25}$ Hadi Al- Anbari and Azeez Hasan compared antioxidant activity in some Citrus leaves and seeds ethanolic extracts. ${ }^{26}$ Kicel et al. correlated phenolic profile and antioxidant potential of leaves from selected Cotoneaster species. ${ }^{27}$ Angel et al. correlated phenolics with antioxidant activity in five underutilized starchy Curcuma species. ${ }^{28}$ Khanavi et al. compared antioxidant activity and total phenols of some date varieties. ${ }^{29}$ Rathi and Rajput reviewed anthocyanins antioxidant potential of grapes. ${ }^{30}$ Oliveira et al., quantified total phenolic content and antioxidant activity of Malvaceae species. ${ }^{31}$ Goodarzi et al., evaluated antioxidant potential and reduction capacity of some plant extracts in silver nanoparticles synthesis. ${ }^{32}$ Camatari analyzed antioxidant potential of flours from cereals, tubers, beans and seeds and also chemical profile of Curcuma longa flour. ${ }^{33}$ Vadlapudi and Naidu analyzed in vitro antioxidant capacity of few selected medicinal and mangrove species. ${ }^{34}$ Figueiredo and Lima, accessed antioxidant activity of anthocyanins from Sideroxylon obtusifolium fruits. ${ }^{35}$ Vaidya et al. compared antioxidant capacity of fresh and dry leaf extracts of sixteen Scutellaria species. ${ }^{36}$ Gandhiappan and Rengasamy compared antioxidant activity of different species of Solanaceae. ${ }^{37}$ Medina-Medrano et al. fractionated phenolic constituents and antioxidant properties of five wild species of Physalis. ${ }^{38}$ Sulniute et al comprehensively evaluated antioxidant potential of selected Salvia species using high pressure methods for the isolation of lipophilic and hydrophilic plant fractions. ${ }^{39}$ In the present study, anthocyanins from Osbeckia species also showed optimal varied AOX potentials as revealed by the results.

The mode of activity of anthocyanins as antioxidants may be a) decreasing localized oxygen concentrations; (b) preventing chain initiation by scavenging reactive oxygen and/or nitrogen species (ROS/RNS), e.g., superoxide anion, hydrogen peroxide, hydroxyl radical, peroxynitrite; (c) binding metal ions in such a manner that they will not generate species such as $\mathrm{HO}$, ferryl or $\mathrm{Fe} 2+/ \mathrm{Fe} 3+/ \mathrm{O} 2$, and/or decompose lipid peroxides to peroxyl and alkoxyl radicals; (d) decomposing peroxides by converting them to non-radical products, such as alcohols; (e) chain-breaking, i.e. scavenging intermediate radicals, such as peroxyl and alkoxyl radicals, to prevent continued hydrogen abstraction. ${ }^{40,41}$

Antioxidant assays in foods and biological systems can be classified into analysis of lipid peroxidation, or measuring the free radical scavenging ability. ${ }^{41}$ In assessing lipid peroxidation, several lipid substrates can be used and the AOX activity in these systems can be analysed by measuring the substrate and the oxidant consumption, and the intermediates or the end products formation. For evaluation of free radical scavenging potential, there are methods such as chemical reactions involved: electron transferand hydrogen transfer-based assays or evaluating effectiveness against several ROS and RNS $\left(\mathrm{O}_{2}, \mathrm{OH}, \mathrm{ONOO}-, \mathrm{NO}, \mathrm{H}_{2} \mathrm{O}_{2}\right) .{ }^{42}$ The AOX capacity of anthocyanins present in diverse fruits has been carried out with diverse assay methods: oxygen radical absorbance capacity (ORAC), a hydrogen transfer-based assay; ferric reducing antioxidant potential (FRAP), trolox equivalent antioxidant capacity (TEAC), and 2,2-diphenyl-1-picrylhydrazyl (DPPH) free radical scavenging activity, all of them are electron transfer-based assays. ${ }^{43-45}$ Scavenging activity towards superoxide; peroxynitrite (ONOO-) scavenging activity; inhibition of human low-density lipoprotein (LDL and liposome oxidation); inhibition of lipid peroxidation; ability to bind heavy metals such as iron, zinc and copper and induction of antioxidant enzymes such as gluthatione-Stransferase (GST), gluthatione reductase (GR), gluthatione peroxidise (GPx) and superoxide dismutase. ${ }^{46-50}$ Fundamentally, this activity is dependent on the chemistry of anthocyanins and not all of them show similar activities for scavenging ROS and RNS. The antioxidant ability of anthocyanins depends on the basic structural orientation of the compound because the ring orientation will decide the way by which a hydrogen atom from a hydroxyl group can be donated to a free radical as well as the potentiality of the anthocyanin to support an unpaired electron. ${ }^{51}$ In addition, the power to scavenge diverse ROS differs among anthocyanins for instance, delphinidine is active against the (being followed by cyanidin and pelargonidin) and pelargonidin is effective against the $\mathrm{OH}$ radical. ${ }^{52}$ Generally the AOX activity of anthocyanins is connected with the number of free $\mathrm{OH}$ around the pyrone ring. More number of $\mathrm{OH}$, the higher is antioxidant activity. Anthocyanins with their 3',4'-dihydroxy groups can chelate metal ions easaily to form stable anthocyanin-metal complexes. ${ }^{53}$ Anthocyanins at $\mathrm{pH}$ 2-4 mostly exist in the form of flavylium cations and because of the charge distribution they are susceptible to nucleophilic attack on positions 2 and 4 . Therefore it can be postulated that the hydroxylation of an anthocyanin at these positions increases its chelating capacity, protecting, for example, ascorbic acid from metal-induced oxidation.

Anthocyanins with the ortho-dihydroxyl groups have the potential to scavenge $\mathrm{OH}$ radicals through the inhibition of $\mathrm{OH}$ generation by chelating iron. ${ }^{54}$ In addition to the degree and position of $\mathrm{OH}$ groups in the $\mathrm{B}$ ring on the AOX activity of anthocyanins, the degree and position of methoxyl groups also influenced the stability and reactivity of these pigments, consequently their AOX activities. ${ }^{47}$ Kähkönen and Heinonen showed that malvidin-3-glucoside and petunidin-3-glucoside showed lower efficacy compared to cyanidin-3-rutinoside and delphinidin3 -glucoside. ${ }^{55}$ Free radical mechanism for the semiquinone stabilization formed from the cyanidin oxidation proposed by Castañeda-Ovando et al..$^{56}$

Similarly, the activities are also dependent on type of reactive species. Muselík et al. reported that for the FRAP and TEAC assays the methoxylation of hydroxyl groups in 5' (petunidin-3-monoglucoside) or 3' and $5^{\prime}$ positions (malvidin-3-monoglucoside) significantly reduced the antioxidant activity. ${ }^{47}$ However, the AOX activity showed by malvidin3 monoglucoside in peroxynitrite mediated tyrosine nitration was the same as that of delphinidin-3-monoglucoside and cyanidin-3rutinoside activities. The activity of anthocyanins in inhibiting tyrosine nitration decreased in the following order: cyanidin-3rutinoside $>$ malvidin3-monoglucoside $\approx$ delphinidin-3 monoglucoside $>$ petunidin-3-monoglucoside. ${ }^{47}$ Tsuda et al. revealed that ONOO- scavenging activity of pelargonidin (anthocyanidin) consists firstly in the break of this pigment by the radical with the formation of p-hydroxybenzoic and secondly the reaction of this acid with ONOO- resulting in the formation of 4-hydroxy-3nitrobenzoic acid. ${ }^{57}$

Depending on the $\mathrm{pH}$, the relative proportions of protonated, deprotonated, hydrated, and isomeric forms of anthocyanins occur. These forms play a role in the AOX activity. In addition, the relative proportions of peroxynitrite anion (ONOO-) and its conjugate acid (HOONO), with different reactivities, are strongly dependent on $\mathrm{pH}$. The peroxynitrite scavenging activity of anthocyanins at $\mathrm{pH} 7.4(\approx 80 \%$ of peroxynitrite was in the anionic form) decreased in the following order: cyanidin3-rutinoside $>$ malvidin-3monoglucoside $\approx$ delphinidin-3-mono-glucoside $>$ petunidin-3monoglucoside. ${ }^{47}$ Anthocyanins glycisylation in fruits and vegetables decrease the AOX capacity by reducing free hydroxyls and metal chelation sites. However, Kähkönen and Heinonen, ${ }^{55}$ reported that depending on the anthocyanidin and lipid oxidation models used for antioxidant analysis, different glycosylation patterns either enhance or diminish the AOX power i.e., activities of the glycosides and the aglycons did not differ remarkably in emulsion, whereas in LDL the aglycons showed in general higher activities than the glycosides. In contrast, in bulk oil, the glycosides were more effective than the aglycons. 
Comprehensive evaluation of antioxidant potential of selected Osbeckia species and their in vitro culture, purification and fractionation

Therefore, the in vitro effect of glycosylation on antioxidant activity also depends on the environment in which oxidations accounts. ${ }^{51}$ Different number of sugar residues and their position in the anthocyanidin may also have different roles on the AOX activity of an anthocyanin. ${ }^{52,55}$ The number of sugar residues at the $\mathrm{C} 3$ position seems to be unique for $\mathrm{AOX}$ activity. The smaller the number of sugar units at $\mathrm{C} 3$, the greater the AOX activity i.e., delphinidin and cyanidin-3-rutinoside are less active in the DPPH scavenging activity than their corresponding monoglucosides. ${ }^{47}$ For example, the glycosylation of malvidin-3-monoglucoside to malvidin-3, 5 diglucoside significantly reduces the AOX ability when measured through the TEAC method, but without significant effect on the inhibition of tyrosine nitration (ONOO- scavenging), or being better as scavenging free radicals when measured through the FRAP assay when compared to malvidin-3-monoglucoside. ${ }^{47}$ The presence of acyl groups also shows influence on the AOX activity, nevertheless and as reported for sugar moieties, the scavenging activity is highly dependent on the type of free radicals. Similarly, pyranoanthocyanins of cyanidin, petunidin, malvidin and pelargonidin showed significant capacity to scavenge superoxide anion radicals but did not scavenge $\mathrm{OH}$ radicals. ${ }^{58}$ Incorporation of pyruvic acid into delphinidin-3-monoglucoside and malvidin-3monoglucoside caused significant decrease in AOX activity in aqueous phase assays. ${ }^{47}$ In the present study the purified anthocyanin contain malvidin 3 glucosides, peonydine, delphynidine and cyanidin. The significant AOX activity showed by the species may be considered as a culmination of activities attributed by these compounds.

\section{CONCLUSION}

Osbeckia species contain optimal anthocyanin and therefore display potential AOX power. O. aspera and O. reticulata were subjected to in vitro culture using optimal concentrations of hormones in the MS medium. Callus was further induced by altering the hormones for in vitro production of anthocyanins. Further, the pool anthocyanins were purified and fractionated by LC-MS/MS. As the last phase, AOX assays were performed with the purified anthocyanin which showed higher level activities. Further studies are planned to analyse the antiinflammatory potential of the purified anthocyanin from these two species.

\section{ACKNOWLEDGEMENT}

The authors acknowledge Kerala State Council for Science, Technology and Environment (KSCSTE) for funding he project and also UGC, Bangalore for providing FIP fellowship for doing Ph. D.( No.FIP/12th Plan/ KLKE 028/ TF 10 dated 19/01/2016).

\section{CONFLICT OF INTEREST}

The authors have no conflict of interest.

\section{ABBREVIATION USED}

MS: Murashige and Skoog; BAP: Bezyl amino purine; KIN: Kinetin; NAA: Naphthalene Acetic Acid; 2,4-D: 2,4 dichloro phenoxy acetic acid; IAA: Indole-3 -acetic acid.

\section{REFERENCES}

1. Thabrew MI, Joice PD, Rajatissa WA. comparative study of the efficacy of Pavetta indica and Osbeckia octandra in the treatment of liver dysfunction. Planta Med. 1987;53(3):239-41.

2. Jayathilaka KAPW, Thabrew MI, Pathirana C, De Silva DGH, Perera DJB. An evaluation of the potency of Osbeckia octandra and Melothria maderaspatana as antihepatotoxic agents. Planta Medica.1989;55(2):137-9.

3. Thabrew MI, Hughes RD, Gove CD, Portmann B, Williams R, McFarlane IG. Protective effects of Osbeckia octandra against paracetamol-induced liver injury. J Xenobitica. 1995;25(9):1009-17.

4. Sujina I, Ravi S. In vitro antimicrobial and cytotoxic activity of methanolic extract of Osbeckia wynaadensis. International Journal of Biological Sciences. 2012;1(4):33-8

5. Syiem D, Khup PZ. Study of the Traditionally Used Medicinal Plant Osbeckia chinensis for Hypoglycemic and Anti-hyperglycemic Effects in Mice. Pharmaceutical Biology. 2006;44(8):613-8.

6. Sharma HM, Devi AR, Sharma BM. Vegetable dyes used by the Meitei Community of Manipur. Indian J Traditional Knowledge. 2005;4(1):39-46.

7. Sutharut J, Sudarat J. Total anthocyanin content and antioxidant activity of germinated colored rice. Inter Food Res J. 2012;19(1):215-21.

8. Manzocco L, Anese M, Nicoli MC. Antioxidant properties of tea extracts as affected by processing. Lebens-mittel-Wissenschaft Und-Technologie. 1998;31(7-8):694-98.

9. Seeram NP, Henning SM, Lee R, Niu Y, Scheuller HS, Heber D. Catechin and caffeine contents of green tea dietary supplements and correlation with antioxidant activity. J Agric Food Chem. 2006;54:1599-603.

10. Benzie IFF, Strain JJ. Ferric reducing antioxidant power assay: Direct measure of total antioxidant of biological fluids and modified version for simultaneous measurement of total antioxidant power and ascorbic acid concentration. Methods in Enzymology. 1999;229:15-27

11. Dinis TCP, Madeira VMC, Almeida LM. Action of phenolic derivatives (acetoaminophen, salycilate and 5-aminosalycilate) as inhibitors of membrane lipid peroxidation and as peroxyl radical scavengers. Arch Biochem Biophys. 1994;315:161-9.

12. Ohkawa H, Ohishi N, Yagi K. Assay for lipid peroxides in animal tissues by thiobarbituric acid reaction. Anal Biochem. 1979;5: 351-8.

13. Prieto P, Pineda M, Aguilar M. Spectrophotometric quantitation of antioxidant capacity through the formation of a phosphomolybdenum complex: specific application to the determination of vitamin E. Anal Biochem. 1999;269(2):337-41.

14. Ruch RJ, Cheng SJ, Klaunig JE. Prevention of cytotoxicity and inhibition of intercellular communication by antioxidant catechins isolated from Chinese green tea Carcinogen. 1989;(10):1003-8

15. Kunchandy E, Rao, MNA. Oxygen radical scavenging activity of curcumin. Int. J. Pharm. 1990;58: 237-40

16. Robak J, Gryglewski RJ. Flavonoids are scavengers of superoxide anions Biochem. Pharmacol. 1988;37(5):837-41.

17. Todaro A, Francesco C, Paolo R, Anna E, Riccardo N, Giovanni S. Recovery of anthocyanins from eggplant peel. Food Chemistry. 2009;(114):434-9

18. Kang YJ, Jung SW, Lee SJ. An optimal extraction solvent and purification adsorbent to produce anthocyanins from black rice (Oryza sativa cv. Heugjinjubyeo). Food Science and Biotechnology. 2014;23(1):97-106.

19. Baskar R, Shrisakthi S, Sathyapriya B, Shyampriya R, Nithya R, Poongodi P. Antioxidant potential of peel extracts of banana varieties (Musa sapientum). Food and Nutrition Sciences. 2011;(2):1128-33.

20. Subhasree BR, Baskar R, Laxmi Keerthana RL, Susan P, Rajasekaran. Evaluation of antioxidant potential in selected green leafy vegetables. Food Chemistry. 2009;115(4):1213-20

21. Umamaheswari $\mathrm{M}$, Chatterjee TK. In vitro antioxidant activities of the fractions of Coccinia grandis L. leaf extract. African Journal of Traditional Complementary and Alternative Medicine. 2008;5(1):61-73

22. Saito KM, Kohno F, Yoshizaki, Niwano Y. Extensive screening for edible herbal extracts with potent scavenging activity against superoxide anions. Plant Foods for Human Nutrition. 2008;63(2):65- 70.

23. Raghavan G, Vijayakumar M, Mehrotra S. Free radical scavenging potential of Chlorophytum tuberosum Baker. Journal of Ethnopharmacology. 2003; 104(3):423-5.

24. Fernando AAG, Gil JAQ, Jiménez NDS, Arango GJA, Weniger B. Antioxidant potential of some species of the genus Bomarea (Alstroemeriaceae) Vitae. Revista De La Facultad De Qu"Mica Farmacutica. 2011;18(2):201-7

25. Venugopalan P, Revathy KT. Antioxidant activity of Cassia fistula flower extracts J. Pharm. Appl. Chem. 2016;2(2):77-80.

26. Hadi Al A K, Anbari, Azeez HM. Antioxidant activity in some Citrus leaves and seeds ethanolic extracts. International Conference on Advances in Agricultural, Biological \& Environmental Sciences. 2015; July 22-23, London(UK)

27. Kicel A, Michel P, Owczarek A, Marchelak A, 'Zy'zelewicz D, Budryn G, et al. Phenolic Profile and Antioxidant Potential of Leaves from Selected Cotoneaster Medik. Species Molecules. 2016;21(6):1-17.

28. Angel GR, Vimala B, Bala N. Phenolic content and antioxidant activity in five underutilized starchy Curcuma species. International Journal of Pharmacognosy and Phytochemical Research. 2012;4(2):69-73.

29. Khanavi M, Saghari Z, Mohammadirad A, Khademi R, Hadjiakhoondi A Abdollahi M. Comparison of antioxidant activity and total phenols of some date varieties. DARU. 2009;17(2):104-8

30. Rathi P, Rajput CS. Antioxidant potential of grapes (Vitis vinifera): a review Journal of Drug Delivery and Therapeutics. 2014;4(2):102-4.

31. Oliveira AMF de, Pinheiro LS, Pereira CKS, Matias WN, Gomes RA, Chaves OS et al. Total Phenolic Content and Antioxidant Activity of Some Malvaceae Family Species. Antioxidants. 2012;1:33-43

32. Goodarzi V, Zamani H, Bajuli L, Moradshahi A. Evaluation of antioxidant potential 
and reduction capacity of some plant extracts in silver nanoparticles synthesis. Molecular Biology Research Communications. 2014;3(3):165-74.

33. Camatari FOS, Lopes KH, Valentim BI, Xavier JA, da Costa JG.) Antioxidant Potential of Flours from Cereals, Tubers, Beans and Seeds Chemical Profile of Curcuma longa Flour. J Nutr Food Sci. 2016;6(483):1-8.

34. Vadlapudi V, Naidu K C. In vitro antioxidant capacity assay of few selected medicinal and mangrove plants. Asian Journal of Chemistry. 2011;23(3):1244-6.

35. Figueiredo FJ, Lima VLAG. Antioxidant activity of anthocyanins from quixabeira (Sideroxylon obtusifolium) fruits. Rev Bras PI Med Campinas. 2015;17(3):473-9.

36. Vaidya, Brajesh N, Terri A, Brearley, Nirmal J. Antioxidant Capacity of Fresh and Dry Leaf Extracts of Sixteen Scutellaria Species. Journal of Medicinally Active Plants 2. 2014;2(3-4):42-9

37. Gandhiappan J, Rengasamy R. Comparative study on antioxidant activity of different species of Solanaceae family. Advances in Applied Science Research. 2012:3(3):1538-44.

38. Medina-Medrano J R, Almaraz-Abarca N, González-Elizondo M S, Uribe-Soto J N, González-Valdez L S, Herrera-Arrieta Y. Phenolic constituents and antioxidant properties of five wild species of Physalis (Solanaceae). Bot Stud. 2015;56(24):1-13.

39. Sulniute $V$, Ragazinskiene $O$, Venskutonis PR. Comprehensive evaluation of antioxidant potential of 10 salvia species using high pressure methods for the isolation of lipophilic and hydrophilic plant fractions. Plant Foods Hum Nutr. 2016;71(1):64-71.

40. Dai J, Mumper RJ. Plant phenolics: extraction, analysis and their antioxidant and anticancer properties. Molecules. 2010;15(10):7313-52.

41. Miguel MG. Antioxidant activity of medicinal and aromatic plants- A review. Flavour and Fragrance Journal. 2010;25(5):291-312

42. Apac R, Güçlü K, Demirata B, Özyürek M, Celil SE, Bektasoglu B, et al. Comparative evaluation of various total antioxidant capacity assays applied to phenolic compounds with the CUPRAC assay. Molecules. 2007;12:1496-47.

43. Steed LE, Truong VD. Anthocyanin content, antioxidant activity, and selected physical properties of flowable purple-fleshed sweet potato purees. J Food Sci. 2008;73:S215-21.

44. Solomon A, Golubowicz S, Yablowicz Z, Grossman S, Bergman M, Gottlieb HE, et al. Antioxidant activities and anthocyanin content of fresh fruits of common fig (Ficus carica L.). J Agric Food Chem. 2006;54(20):7717-23.

45. Koca I, Karadeniz B. Antioxidant properties of blackberry and blueberry fruits grown in the Black Sea region of Turkey. Sci Hort. 2009;121(4):447-50.

46. Costantino L, Albasini A, Rastelli G, Benvenuti S. Activity of polyphenolic crude extracts as scavengers of superoxide radicals and inhibitors of xanthine oxidase. Planta Med. 1992;58(4):342-4

47. Muselík J, García-Alonso M, Martín-López MP, Žemlicka M, Rivas-Gonzalo JC Measurement of antioxidant activity of wine catechins, procyanidins, anthocyanins and pyranoanthocyanins. Int J Mol Sci. 2007;8(8):797-809.

48. Heinonen I M, Meyer AS, Frankel EN. Antioxidant activity of berry phenolics on human low-density lipoprotein and liposome oxidation. J Agric Food Chem. 1998;46(10):4107-112.

49. Havsteen B. Flavonoids, a class of natural products of high pharmacological potency. Biochem Pharmacol. 1983;32(7):1141-8.

50. Turner MK. Anthocyanins increase antioxidant enzyme activity in HT-29 adenocarcinoma cells. MsC thesis. 2009. Athens, Georgia, USA

51. Kay C. Analysis of the bioactivity, metabolism, and pharmacokinetics of anthocyanins in humans. PhD thesis. 2004: University of Guelph, Ontario, Canada, pp. 1-9

52. Antal DS, Gârban G, Gârban Z. The anthocyanins: biologically active substances of food and pharmaceutic interest. The Annals of the University. Dunarea de Jos of Galati. Food Technol. 2003;6:106-15.

53. Sarma AD, SreelakshimiY, Sharma R. Antioxidant ability of anthocyanins against ascorbic acid oxydation. Phytochem. 1997; 45: 671- 74.

54. Bakowska-Barczak A. Acylated anthocyanins as stable, natural food colorants-a review. Pol J Food Sci. 2005;14:107-16.

55. Kähkönen MP, Heinonen M. Antioxidant activity of anthocyanins and their aglycons. J Agric Food Chem. 2003;51(3):628-33.

56. Castañeda-Ovando A, Pacheco-Hernández ML, PáezHernández ME, Rodríguez JA, Galán-Vidal C. Chemical studies of anthocyanins: a review. Food Chem. 2009;113:859-71.

57. Tsuda T, Shiga K, Ohshima K, Kawakishi S, Osawa T. Inibhition of lipid peroxidation and the active oxygen radical scavenging effect of anthocyanin pigments isolated from Phaseolus vulgaris L. Biochem Pharmacol. 1996;52(7):1033-39.

58. García-Alonso M, Matsugo U, Rimbach G, Rivas Gonzalo JC, de Pascual-Teresa S. Electro spin resonance spectroscopy studies on the free radical scavenging activity of wine anthocyanins and pyranoanthocyanins. Mol Nutr Food Res 2005;49(12):1112-9

\section{GRAPHICAL ABSTRACT}

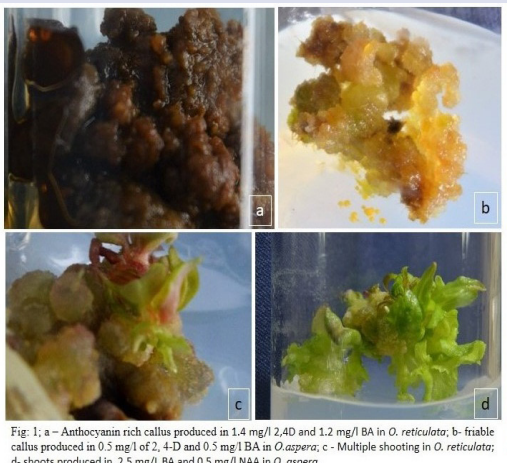

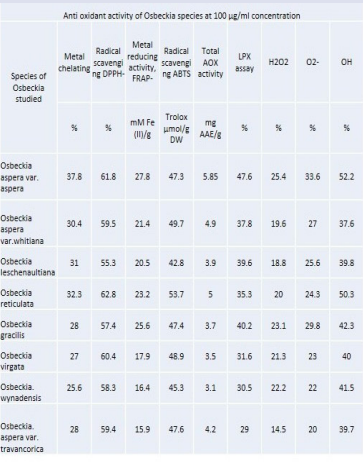

\section{HIGHLIGHTS OF PAPER}

- $\quad$ O. aspera and $O$. reticulata were subjected to in vitro culture using optimal concentrations of hormones in the MS medium.

- In vitro production of anthocyanins was induced by altering the hormones

- The anthocyanins were purified and fractionated by LCMS/MS

- AOX assays were performed with the purified anthocyanins.

\section{AUTHOR PROFILE}

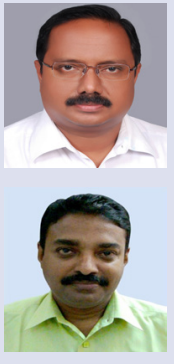

Mr. Bosco Lawarence: is an Assistant Professor of Botany at Govt Arts College, Trivandrum. His current research is in the in vitro production of anthocyanins.

Dr. Murukan K: is the Deputy Director of Collegiate Education(full additional charge), Govt.of Kerala, India. His research areas include the Biochemistry of natual dyes, Stress physiology and Molecular defence mechanisms.

Cite this article : Bosco Lawarence and Murugan K. Comprehensive Evaluation of Antioxidant Potential of Selected Osbeckia species and their in vitro Culture, Purification and Fractionation. Pharmacog J. 2017;9(5):674-82. 